\title{
TODOS OS HOMENS SÃO MAUS, MAS ALGUNS SÃO BONS EXEMPLOS: CONSIDERAÇÕES SOBRE A IMITAÇÃ̃ NO PENSAMENTO MAQUIAVELIANO
}

\author{
Marcone Costa Cerqueira ${ }^{1}$ \\ Universidade Federal de Santa Catarina (UFSC) \\ https://orcid.org/0000-0003-4539-3840 \\ E-mail: markantfilos@yahoo.com.br
}

\section{RESUMO:}

Tencionamos, neste artigo, tratar da questão da imitação no pensamento maquiaveliano. Tomaremos como balizas suas postulações acerca da natureza do homem, as possibilidades de formatação de uma república profícua em vista desta natureza e o papel dos exemplos dos indivíduos que agem em prol do bem da república. Sendo a questão da imitação o fio condutor, elegeremos ainda um tripé para demonstrar nossa hipótese, a saber, o fator antropológico; o fator educacional; o fator político. Por este movimento, pretende-se demonstrar que a aparente negatividade das postulações maquiavelianas sobre a natureza humana não inviabilizam a promulgação de uma república estável, tendo os bons exemplos políticos um papel preponderante neste propósito.

PALAVRAS-CHAVE: Teoria da ação; Maquiavel; Imitação; República.

\section{ALL MEN ARE EVIL, BUT SOME ARE GOOD EXAMPLES: CONSIDERATIONS OF IMITATION IN MACHIAVELLIAN THOUGHT}

\begin{abstract}
:
We intend, in this article, to deal with the issue of imitation in Machiavellian thought. We will take as a goal his postulations about the nature of man, the possibilities of formatting a profitable republic in view of this nature, and the role of the examples of individuals who act for the good of the republic. Since the issue of imitation is the guiding thread, we will still choose a tripod to demonstrate our hypothesis, namely, the anthropological factor; The educational factor; The political factor. By this movement, it is tried to demonstrate that the apparent negativity of the Machiavellian postulations on the human nature does not prevent the promulgation of a stable republic, the good political examples having a preponderant role in this purpose.
\end{abstract}

KEYWORDS: Theory of action; Machiavelli; Imitation; Republic.

\footnotetext{
1 Doutorando em Filosofia na Universidade Federal de Santa Catarina (UFSC), Florianópolis - SC, Brasil. Bolsista Capes.
}

CERQUEIRA, Marcone Costa. Todos os homens são maus, mas alguns são bons exemplos: considerações sobre a imitação no pensamento maquiaveliano. Griot : Revista de Filosofia, Amargosa - BA, v.18, n.2, p.14-33, dezembro, 2018. 


\section{Introdução}

A aparente negatividade presente na definição de uma natureza humana em Maquiavel suscitou inúmeras discussões sobre a viabilidade de se pensar em um direcionamento republicano a partir da própria constituição dos indivíduos. "Como podem ser impedidos de decair para a corrupção, como podem ser forçados a manter o interesse pelo bem comum por um período longo o suficiente para que se alcance a grandeza cívica?" (SKINNER, 2012. p. 81). Como poderiam se assentar as bases de uma virtude cívica se o homem tem como um de seus traços mais profundos a disposição ao mal? Qual a viabilidade de se postular instituições políticas incólumes e livres se os indivíduos são avessos, por predisposição, ao que é justo e bom? Em uma leitura estreita e superficial da obra do florentino, realmente poderia se intuir que sua percepção sobre o homem inviabiliza a proposta republicana de um arranjo social baseado na justiça, na liberdade e na busca do bem comum. Esse aparente problema é suprido, na Modernidade, pela extrema inflação da conceitualização das ideias de justiça e igualdade, uma predominância do formal sobre o material, o domínio do conceito sobre a tradição e as relações sociais diretas ${ }^{2}$.

No entanto, é preciso desobstruir alguns pontos que parecem estar solapados por leituras genéricas e ortodoxas sobre os principais conceitos presentes no pensamento maquiaveliano. As colocações feitas por Maquiavel sobre uma aparente disposição do homem ao mal não buscam ancorar uma antropologia sistemática, mas, também não se restringem a uma rasteira instrumentalidade políticolegislativa. Mais que isso, a tessitura da teia de pensamento deste autor é intricada e profunda, não se pode amputar trechos, por mais assertivos que sejam, em nome de uma interpretação procustiana.

Em vista disto, para se confrontar o dilema existente em se pensar uma república que se sustente por bases estabelecidas por vias de instituições justas, livres, erigidas e mantidas por indivíduos portadores de predisposições corruptas, deve-se: I - compreender as implicações contidas na postulação do mal no homem por Maquiavel, o fator antropológico; II - como pode se validar uma preocupação em se estabelecer parâmetros cívicos de ação, ou seja, atitudes que sejam valoradas no contexto social, principalmente por meio da busca da imitação dos bons exemplos, o fator educacional; III - como estes exemplos são vistos, inseridos e reconhecidos (mérito) em um contexto cultural que fortaleça a busca de ações que privilegiem o bem comum, o fator político.

Este itinerário, à primeira vista, pode parecer ainda deficitário, no entanto, seu objetivo é demonstrar as bases que assentam, de forma sucinta, o edifício maquiaveliano em sua busca de pautar a valorização das ações individuais no

2 Sobre esta afirmação, recomendamos que se leia a obra: A filosofia e o espelho da natureza, de Richard Rorty. Nela o autor aborda a tradição filosófica dominante no início da Modernidade, desde Descartes, e seu impulso a tratar o mundo natural como reflexo das apreensões possíveis pela mente. Tal apreensão é possível por uma espécie de 'olho da mente', que tudo vê e conceitualiza. Este movimento culmina em Kant, no qual a ideia do filósofo como construtor de conceitos se solidifica e toma corpo. Acreditamos que este movimento se incrustou no âmbito do pensamento político e favoreceu ao que chamamos nesta assertiva de inflação da conceitualização.

CERQUEIRA, Marcone Costa. Todos os homens são maus, mas alguns são bons exemplos: considerações sobre a imitação no pensamento maquiaveliano. Griot : Revista de Filosofia, Amargosa - BA, v.18, n.2, p.14-33, 
contexto político, demonstrando a viabilidade de se constituir um governo profícuo através de instituições livres, justas e estáveis. Além disso, a necessidade de se estabelecer política e culturalmente a valorização dos indivíduos que servem como exemplo de ação cívica, ação essa que só é valorada em suas consequências para o bem comum.

O fio condutor deste itinerário é sem dúvidas a ideia de imitação, presente em Maquiavel, bem como em Lívio, Cícero, Aristóteles e diversos outros autores da Antiguidade. A busca da imitação das ações de indivíduos valorosos também está realçada na cristandade, no entanto, como buscaremos demonstrar, a maneira de se compreender a natureza humana, o fator antropológico; o direcionamento de utilização dos exemplos na educação dos jovens, o fator educacional; bem como a valorização e o reconhecimento político e cultural, o fator político; são bem distintos em vista dos pontos que são tomados como dignos de relevo na ação dos indivíduos. Tomemos o seguinte trecho dos Discorsi, no qual Maquiavel aponta sucintamente esta questão:

\begin{abstract}
Pensando, portanto, donde possa nascer, que, naqueles tempos antigos, os povos fossem mais amantes da liberdade que neste; creio nasça daquela mesma causa que faz agora os homens menos fortes: a qual creio seja a diversidade da nossa educação em relação à antiga. Porque, havendo a nossa religião mostrado a verdade e o verdadeiro caminho, se faz estimar menos a honra mundana: onde os gentios, estimando-a bastante, e havendo posto nisso o sumo bem, eram em suas ações mais ferozes. [...]. A nossa religião tem glorificado mais os homens humildes e contemplativos, que os ativos. Tendo ainda posto o sumo bem na humildade, abnegação e no desprezo das coisas humanas; enquanto a outra o colocou na grandeza de ânimo, na fortaleza do corpo, e em todas as outras coisas capazes de fazer o homem fortíssimo.(MACHIAVELLI, 1954, D. II, 2).
\end{abstract}

Este passo é bem conhecido e bastante utilizado para se pautar a crítica maquiaveliana à religião cristã, principalmente em seu ramo católico. No entanto, extrairemos daqui alguns bastiões para sustentar nossa argumentação em vista de demonstrar nossa tese. Temos aqui os três fatores elencados, primeiro a compreensão da busca de um bem humano, um valor à ser "aderido" à ação do homem em vista de sua natureza ${ }^{3}$, ou seja, uma compreensão do humano que delineia sua atividade no contexto social. Certamente que a compreensão antropológica expressa pelo cristianismo aponta para uma natureza totalmente diversa daquela, aparentemente instrumental, indicada por Maquiavel.

O segundo ponto claramente destacado é a preocupação com a educação dos jovens em vista dos exemplos à serem seguidos, a valorização das ações dos indivíduos que se sobressaem na defesa da liberdade e do bem comum, o amor pela liberdade é o amor pela pátria. $O$ terceiro ponto é a valorização, política e cultural, e

3 Esta assertiva pode ser fonte de inúmeras detrações, uma vez que parece apontar para influências muito pouco traçadas no pensamento maquiaveliano, principalmente por parte da tradição aristotélica. Maquiavel usa o termo "sommo bene", mas, isso não é o indicativo de que sua orientação esteja pautada por um aristotelismo sistemático ou platonismo. No entanto, indicamos que o autor está se remetendo ao entendimento, em cada uma das duas tradições, de um fim próprio para o homem em sua natureza, ou seja, para os antigos, o fim supremo do homem é a busca da glória e a fortaleça do corpo, já para os modernos, tal fim é a contemplação e a busca de uma glória alcançada no plano espiritual, não temporal.

CERQUEIRA, Marcone Costa. Todos os homens são maus, mas alguns são bons exemplos: considerações sobre a imitação no pensamento maquiaveliano. Griot : Revista de Filosofia, Amargosa - BA, v.18, n.2, p.14-33, 
a busca do reconhecimento das ações dos indivíduos em vista da busca da glória ${ }^{4}$. Como é óbvio, e truisticamente posto por inúmeros autores, a diferença entre as duas tradições, a antiga e a cristã, é o mote da asserção maquiaveliana, no entanto, o destaque principal é o amor à liberdade. Não nos prenderemos muito neste antagonismo, já que é o movimento mais empreendido pelos autores que abordam o tema, porém, nos voltaremos para a resolução do problema inicialmente posto. Como pensar a possibilidade de uma república livre, justa e estimuladora de ações que exprimam uma virtude cívica indispensável à construção de uma sociedade estável e livre, isto em face de uma antropologia aparentemente negativa e instrumental? Através dos pontos propostos anteriormente buscaremos justificar nossa hipótese de que a assertiva maquiaveliana sobre a natureza do homem não inviabiliza a busca de um ideal republicano e tem como fio condutor a ideia de imitação em vista dos valores aceitos e preconizados no contexto social.

\section{O fator antropológico}

"A chave para se compreender melhor o pensamento de Maquiavel consiste consequentemente em uma correta compreensão de sua antropologia, pois essa constitui-se a base de seu pensamento político."(PINZANI, 2006. p. 67) A questão sobre a natureza do homem, expressa por Maquiavel, é o mote de uma ampla discussão acerca da utilidade política de uma antropológica concepção de mal. Há defensores da tese de que o florentino segue um pessimismo cristão, uma visão decaída e decrépita do homem. Como é a opinião de Haslam (2006, p.52): “Os comentários de Maquiavel sobre a natureza do homem são esparsos mas estão em perfeita consonância com um pessimismo agostiniano". Outros, indicam um nítido caráter instrumental direcionado à formatação do substrato legislativo, por parte dos magistrados ou fundadores, bem como do substrato político das instituições de um Estado. A esse respeito argumenta Ames (2002, p. 96):

\footnotetext{
O significado para Maquiavel, insistimos, não é a descrição da natureza humana como corrupta, no sentido antropológico. Antes, o fato de partir de uma pressuposição fundamentalmente pessimista acerca da natureza humana tem uma finalidade prática: partindo da hipótese da maldade humana, pode considerar cada vez a situação mais difícil da ação política.
}

Em nossa argumentação, ponderamos que a segunda perspectiva é mais próxima de uma coerência interna do escopo geral da obra maquiaveliana. No entanto, limitar a concepção maquiaveliana a um simples instrumentalismo políticolegislativo parece ser temerário e tacanho. $O$ interesse de Maquiavel não é estabelecer uma antropologia que demande profundo estudo ontológico, teológico ou mesmo sistemático, como bem apontou Namer (1961, p. 98):

Maquiavel não estuda o mecanismo do homem em geral para examinar em seguida como este mecanismo se encontra empenhado na vida social. Ele

\footnotetext{
4. Veremos mais à frente esta questão da glória em Maquiavel de forma mais detalhada, principalmente em seu movimento retórico de elencar as ações que merecem mais glória: a fundação de religião, a fundação de Estado e a conquista militar.
}

CERQUEIRA, Marcone Costa. Todos os homens são maus, mas alguns são bons exemplos: considerações sobre a imitação no pensamento maquiaveliano. Griot : Revista de Filosofia, Amargosa - BA, v.18, n.2, p.14-33, 
não se pergunta como o homem abstratamente definido se comportaria na presença de tais categorias de seus iguais, em uma situação psicológica dada; ele não estuda o homem em si, como o faz Jean-Jacques Rousseau, que tem descoberto uma bondade primitiva e um sentimento que nos é dado por Deus para nos levar em direção à ordem.

Sua meta é oferecer uma diretriz de partida para demonstrar que uma sociedade é feita de indivíduos diversos, mas, que possuem uma predisposição em comum. É esta a perspectiva que acolhemos nestas considerações sobre a assertiva proposta por Maquiavel. Em outros termos, podemos afirmar que a assertiva maquiaveliana: "todos os homens são maus", carrega um caráter dedutivo-universal. No entanto, sua intenção não parece ser a de estabelecer uma lógica dedutiva que apenas justifique uma natureza errática do homem, antes, esse movimento assenta uma das bases de seu pensamento.

Os homens só podem ser julgados pelas consequências de suas ações, a materialidade da ação, mais que sua intenção movente, é o fator à ser apreciado num movimento valorativo. Mas, o legislador, até mesmo os indivíduos na sociedade, não conhecem tais consequências antes de se concretizarem as ações, obviamente, em todas as suas extensões. Neste caso, o princípio dedutivo é um dispositivo de segurança, uma maneira de equiparar todos os homens, uma vez que não se conhece as consequências das ações a priori, simplesmente por seu móbil intencional. Por este prisma podemos intuir que o fator temporal é um determinante na lógica de estabelecimento da regra imposta pelo florentino, somente o tempo, juntamente à experiência, desvelará as consequências das ações dos indivíduos. No dizer do próprio autor:

\footnotetext{
... e estão sempre prontos a usar a maldade de seus ânimos todas as vezes que têm livre ocasião; e quando alguma maldade está oculta por um tempo, procede de uma razão oculta, que por não se ter experiência do contrário, não se conhece; mas a faz, pois, descobrir o tempo, o qual dizem ser pai de toda verdade. (MACHIAVELLI, 1954, D. I, 3.).
}

O legislador não domina o tempo, mas deve legislar em vista do futuro, por isso a necessidade de equiparação da predisposição dos homens e da premissa de que todos são passíveis de cometerem um mau. Além disso, as ações das quais Maquiavel parece partir são aquelas que representam dano ou benefício a terceiros e à própria pátria, não ao próprio indivíduo isoladamente. Ações que representam vícios sociais, os quais põem em risco a estabilidade social, no caso das relações entre os indivíduos, e as que põem em risco a estabilidade de governo, no caso das relações entre indivíduos e governantes. Como aponta Maquiavel:

\footnotetext{
Disto nasce o conhecimento das coisas honestas e boas, diferente das perniciosas e más: porque, vendo que se alguém prejudicava seu benfeitor, suscitava ódio e compaixão entre os homens, maldizendo os ingratos e honrando aqueles que fossem gratos, pensando ainda que aquelas mesmas injúrias podiam ser feitas a eles, para fugir de parecidos males, se puseram a fazer leis, ordenando punições à quem as desobedecesse: de onde vem o conhecimento da justiça. (MACHIAVELLI, 1954, D. I, 2.)
}

CERQUEIRA, Marcone Costa. Todos os homens são maus, mas alguns são bons exemplos: considerações sobre a imitação no pensamento maquiaveliano. Griot : Revista de Filosofia, Amargosa - BA, v.18, n.2, p.14-33, dezembro, 2018. 
Isso nos dá outra indicação da toada assumida por Maquiavel em sua análise da questão do mal nas ações humanas. Ele não se volta para o Mal teológico ou metafísico, não está preocupado, ao que parece, em criar uma teorização éticovalorativa das ações que dizem respeito ao indivíduo isoladamente em sua condição moral. A maldade à qual Maquiavel se refere é aquela que atrapalha o viver em sociedade, as ações que geram a falta de justiça para com os demais indivíduos, não aquela que atrapalha o indivíduo em uma pretensa ascensão moral no âmbito individual. Esta última compreensão de maldade está entrelaçada indelevelmente na construção cristã de uma antropologia teológica, individualmente imputada, mas universalmente conspurcada. Como nos instrui Saranyana (2006, p. 85):

Já o mal moral, o pecado, é o único mal verdadeiro, e procede da livre vontade das criaturas racionais. Como isso é possível? A vontade livre é má? A resposta de Santo Agostinho é clara: a vontade humana, considerada em si mesma, é boa, e o livre arbítrio, em si mesmo, é um bem e condição para alcançar a felicidade; no entanto, a vontade criada é falível, pode equivocar-se, e o exercício do livre arbítrio traz consigo o risco do pecado. Desse modo, a vontade livre torna-se má quando está privada da ordem devida.

A diferença principal entre as perspectivas expressas por Maquiavel e pela tradição cristã está na ação do homem, ou melhor, uma está centrada na consequência da ação, a maquiaveliana, a outra está pautada no móbil da ação, a cristã. Neste sentido, a má ação do homem em Maquiavel é expressa pela consequência que traz ao convívio social, como já indicamos, por isso, a simples intenção de bem agir não garante que tal ação trará benefícios ao bem comum. Ao contrário, na perspectiva cristã, que comporta uma antropologia teológica na qual o mal é expresso na intenção que impulsiona a ação do homem, a vontade, o bem agir do homem é expresso pela pureza de sua intenção, não pelo fato de produzir ou não algum efeito.

Ora, como já explicitamos, o legislador ou fundador de Estado não conhece as intenções dos indivíduos, os próprios indivíduos vivendo em sociedade não conhecem as intenções uns dos outros, sendo assim, a equiparação dos homens é posta em vista das consequências das ações que possam empreender, boas ou más, não nas intenções que possam ter. $O$ caminho inverso é feito pelas teorias baseadas nas virtudes, espirituais ou não, quando tomam como equiparação uma virtude. Ou seja, todo homem pio agirá piedosamente, todo homem justo, agirá justamente. Em Maquiavel, o que interferirá na determinação da execução de uma ação que represente um malefício a terceiros ou à pátria é a ocasião.

No pensamento maquiaveliano acerca do homem e da constituição social, a ideia de ocasião é extremamente importante. Não só como complemento à necessidade de equiparação dos homens em vista de sua predisposição ao mal, mas também na postulação da possibilidade de imitação dos bons exemplos. A ideia de ocasião carrega ainda a prerrogativa da atemporalidade, assim como a ideia de disposição ao mal no homem, como dissemos, o legislador não domina o tempo, mas, legisla para o futuro, ou seja, faz leis que devem regrar a república por muito tempo. Mas, como já foi apontado, ele também não domina a intenção dos indivíduos, no

CERQUEIRA, Marcone Costa. Todos os homens são maus, mas alguns são bons exemplos: considerações sobre a imitação no pensamento maquiaveliano. Griot : Revista de Filosofia, Amargosa - BA, v.18, n.2, p.14-33, 
entanto, ele pode prever as ocasiões nas quais uma ação pode representar um mal a um indivíduo ou ao governo.

Chega-se a uma compreensão da importância da ocasião na argumentação maquiaveliana. Ao se propor uma equiparação dedutiva-universal da natureza do homem, todos os homens são maus, o legislador, ou fundador de Estado, pode se concentrar na deliberação das ocasiões em que os indivíduos são mais tentados a agir de forma a causar prejuízo. Podemos intuir que este movimento funcione como uma projeção ad eternum das situações de interação social dos indivíduos, como seja, as ocasiões nas quais a única válvula de controle é a lei, ou melhor, a punição atrelada a ela.

O cálculo do legislador, tendo como parâmetro a equiparação negativa dos homens bem como a projeção das ocasiões, conta ainda com outro fator que também carrega a prerrogativa da atemporalidade, a saber, as paixões humanas. Em Maquiavel é bem nítida a imagem do homem enquanto um ser passional, guiado por paixões, desejos e ambições. Nas palavras do Florentino:

\begin{abstract}
Não por acaso, ou sem princípio, que os sábios sempre dizem: considere o que foi para saber o que será. Certamente, em todas as épocas o que acontece no mundo tem similaridade com o já ocorrido. Isto provém do fato de que, sendo todas as coisas humanas tratadas por pessoas que têm e terão sempre as mesmas paixões, não podem deixar de apresentar os mesmos resultados. (MACHIAVELLI, 1954, D. III, 43).
\end{abstract}

Os limites de amplitude de nossas considerações neste texto não nos permitem um trato maior destas três ideias, no entanto, as apresentamos sucintamente para ressaltar seu papel nesse conjunto na perspectiva da natureza humana no pensamento maquiaveliano. Este aspecto da perspectiva maquiaveliana sobre uma natureza do homem distingue-se de uma antropologia metafísica ou teológica, principalmente ao que tange à ação das paixões na vida social dos indivíduos. Não é o caos interior, ou moral, causado pelas paixões, que parece interessar à Maquiavel. Em detrimento ao pensamento cristão, para o Florentino, a inquietude humana está direcionada à necessidade de mudança, mas não uma mudança moral, espiritual ou contemplativa, mas, antes uma mudança social, política. Para Maquiavel as paixões dos homens não conhecem limites temporais ou culturais, em todos os tempos e em todos os lugares os homens tiveram e terão sempre as mesmas paixões e inquietações.

Estabelecidos os parâmetros que até aqui foram apresentados, pode-se vislumbrar o papel do fator antropológico no pensamento maquiaveliano. Seu caráter negativo não se presta apenas à instrumentalidade política, antes, ela serve como sustentáculo para outras concepções que dão forma a seu edifício teórico. Parece-nos que guiar o cálculo do legislador, ou fundador de Estado, ao constituir um corpo de leis não é o único objetivo de Maquiavel. A construção de uma malha de possibilidades de leitura da história e consequentemente uma fonte de inúmeros exemplos de virtù e ações cívicas em vistas de determinadas ocasiões, bem como de ações nocivas em vistas de outras ocasiões, é um produto precioso do escopo construído pelo secretário florentino.

Tais leituras são indeléveis para a aplicabilidade da ideia de imitação e para a promulgação de parâmetros de ação que não se baseiem em virtudes universais, mas

CERQUEIRA, Marcone Costa. Todos os homens são maus, mas alguns são bons exemplos: considerações sobre a imitação no pensamento maquiaveliano. Griot : Revista de Filosofia, Amargosa - BA, v.18, n.2, p.14-33, 
antes, em consequências previsíveis dentro do corpo político. Esta configuração será perceptível no entendimento maquiaveliano sobre o papel da educação e do uso dos bons exemplos políticos.

\section{O fator educacional}

Diversos aspectos do pensamento maquiaveliano são tratados com extremo esmero e profundidade, enquanto outros são tidos como correlatos, o que se pode dizer, acontece com a obra de diversos autores clássicos. A questão da educação, em nosso entender, é um destes pontos marginalmente postos nas discussões sobre a obra do Florentino. É certo que Maquiavel, assim como não produziu uma antropologia sistemática, não teve a pretensão de produzir uma pedagogia. No entanto, o peso que ele dá ao papel da educação é enorme, haja vista sua assertiva de que os modernos são menos amantes da liberdade por conta de sua moderna educação.

Por sua vez, a educação está intimamente atrelada à percepção religiosa predominante na sociedade e em sua influência sobre os indivíduos, este conjunto, educação/religião, compõe o "tribunal" no qual serão julgados os exemplos de ações tidos como dignos de imitação no contexto político e social. A preocupação de Maquiavel com os jovens é bem nítida em sua obra, não só com o jovem príncipe, mas com aqueles jovens que devem manter o viço de uma república saudável, bem como aqueles que devem vislumbrar um renovo naquelas que estão decrépitas. Esta preocupação já foi ressaltada por inúmeros comentadores ${ }^{5}$ da obra do secretário florentino, sempre com o afã de demonstrar uma implícita crítica ao cenário contemporâneo do autor e um chamamento à mudança.

Mas, por que Maquiavel se preocuparia com a educação dos indivíduos se todos os homens são maus e sempre prontos a mostrarem sua maldade? Bem, parecenos que a resposta se encontra, se é que ela existe, em consonância com o caráter dedutivo-instrumental de sua concepção de uma natureza do homem. Tomando esta diretriz, podemos confrontá-la, por exemplo, à concepção cristã do homem, na qual a educação serve para suprir a alma de conhecimento em prol de sua descoberta da vontade divina. Podemos ainda tomar a concepção grega do homem, na qual a educação se presta a desvelar o conhecimento intrínseco à alma propriamente humana, a psychê, e moldar o indivíduo para a vida na pólis, através do cultivo das virtudes e das belas ações.

Em ambas as confrontações veremos diferenças essenciais, em relação à perspectiva cristã, Maquiavel parece não acreditar em uma possibilidade de ascensão espiritual e moral do homem, na qual o corpo político se torne reflexo da pureza de tal ascensão. A ideia cristã de que o homem tem a possibilidade de controlar sua disposição ao mal através da adesão à vontade e à lei divina direciona a educação para uma introspeção do indivíduo. Vejamos a indicação de Gilson (2006, p. 252) sobre este ponto:

5 Ver LEFORT, Claude. Les formes de l'histoire: essais d'anthropologie politique. [S.l.]: Gallimard, 1978; GRAMSCI, Antonio. Maquiavel, a política e o Estado Moderno. Tradução de Luiz Mário Gazzaneo. 7 ed. Rio de Janeiro: Civilização Brasileira, 1989.

CERQUEIRA, Marcone Costa. Todos os homens são maus, mas alguns são bons exemplos: considerações sobre a imitação no pensamento maquiaveliano. Griot : Revista de Filosofia, Amargosa - BA, v.18, n.2, p.14-33, 


\begin{abstract}
A natureza é regida necessariamente por essa ordem, que Deus lhe impôs, e o homem, na medida em que é uma parte da natureza, submete-se à ordem divina sem poder subtrair-se dela. Ao contrário, uma diferença capital aparece com as ações que dependem da vontade humana; no lugar de serem necessariamente regidas pela ordem divina, essas ações têm como objeto realizá-la. Aqui, não se trata mais de submeter-se à lei, mas de querê-la e de colaborar com seu cumprimento. $\mathrm{O}$ homem conhece a regra; a questão é se ele a quer. Consequentemente, tudo depende da decisão que o homem tomar ou não tomar, de fazer reinar em si mesmo a ordem que ele vê ser imposta por Deus à natureza. (...) A força de que uma decisão tão importante depende é tão somente à vontade.
\end{abstract}

Não há espaço para a imitação de ações que tragam consequências válidas apenas para um aporte político, na verdade, qualquer ação que não seja resultado da adesão à lei divina é inócua. "Agostinho identifica a fé com a verdadeira vontade de crer: na ausência dessa vontade, nenhuma obra humana pode ser boa. [...]. Na realidade, todos os comportamentos virtuosos que não nascem da fé são corrompidos." (VETÖ, 2005. p. 45). Neste sentido, a imitação dos bons exemplos é na verdade a busca da contemplação para se alcançar, individualmente, o mesmo nível de resignação e humildade daqueles que demonstram fé inabalável. Os homens que desprezam as coisas mundanas, são os heróis de uma religião que renega as ações políticas ao plano corrupto do palco puramente humano. $\mathrm{O}$ indivíduo, na perspectiva cristã, é educado para se destacar como cidadão de sua pátria celestial, sua verdadeira origem.

Para Maquiavel o incentivo à imitação dos indivíduos que agem contundentemente em prol do bem comum é um dos fatores primordiais na tarefa da educação. Neste sentido, o foco não está na virtude movente da ação ou na adesão a um sentimento religioso que se traduza em uma resignação sem consequências efetivas. A própria religião, quando utilizada pelo príncipe ou governante, para incentivar uma ação que se deve esperar dos indivíduos em prol do bem comum, pode ser falseada em suas interpretações e desígnios. Como vemos no seguinte trecho:

Devem portanto os príncipes de uma república ou de um reino, manter os
fundamentos de sua religião, e feito isto, ser-lhes-á fácil manter os
sentimentos religiosos do Estado, a união e os bons costumes. Devem,
ademais, favorecer tudo o que possa propagar esses sentimentos, mesmo
que se trate de algo que se considere falso. E tanto mais o devem fazer,
quanto mais prudentes são, e quanto mais conhecedores das coisas
naturais. (MACHIAVELLI, 1954, D. I, 12).

O papel da educação, ao lado da religião, é o de promulgadora dos modelos de ação que representam um benefício para o bem comum, não o de uma via individual de ascensão moral resignada com o cenário político. A religião, segundo Maquiavel atua diretamente neste processo de organização social e manutenção política, interagindo com as demais instituições sociais, políticas e militares.

Se confrontarmos ainda a perspectiva maquiaveliana à visão grega de educação poderemos elencar essenciais diferenças, apesar de termos algumas importantes similaridades. É certo que a educação do indivíduo grego era a educação para a pólis, ou seja, o indivíduo aprende que o convívio na cidade é o campo fértil

CERQUEIRA, Marcone Costa. Todos os homens são maus, mas alguns são bons exemplos: considerações sobre a imitação no pensamento maquiaveliano. Griot : Revista de Filosofia, Amargosa - BA, v.18, n.2, p.14-33, 
no qual suas virtudes florescerão, bem como suas habilidades. Isso já é uma questão que se aproxima da perspectiva maquiaveliana e destoa da visão cristã, a preconização da educação enquanto preparação do indivíduo para o convívio social, a formação do cidadão. No entanto, se tomarmos esta perspectiva, e ainda uma concepção mais próxima da proposta aristotélica, poderemos perceber ainda uma predominância da valorização do móbil da ação, mais que de sua consequência.

Os gregos tinham um princípio conhecido como paradigma, algo que influenciou muito a educação romana, como veremos mais à frente, e que se tornou um dos pilares da educação grega. "A ideia de se tomar exemplos do passado para formular uma boa linha de conduta se encontra já nos trágicos e nos oradores do século IV antes de nossa era [...]". (NATALI, 2004. p. 17). A tomada dos exemplos, no entanto, não constituem um via de certeza de que as mesmas consequências ocorrerão, isso porque as disposições dos indivíduos são diferentes. Mas, o que se destaca na tradição grega é a ação em vista da produção de uma disposição para determinada virtude, ou seja, o indivíduo que cria uma disposição para a justiça sempre agirá justamente. Neste sentido, a educação é um direcionamento para a prática das virtudes em vista da criação de uma disposição por meio de um hábito. Vejamos a opinião do Estagirita sobre este ponto:

E, portanto, fica evidente que nenhuma das virtudes morais é em nós engendrada pela natureza, uma vez que nenhuma propriedade natural é passível de ser alterada pelo hábito. [...] As virtudes, portanto, não são geradas em nós nem através da natureza nem contra a natureza. A natureza nos confere a capacidade de recebê-las, e essa capacidade é aprimorada e amadurecida pelo hábito. (ARISTÓTELES, [19-], EN II 1103a 1 20-25).

Apesar de atribuir importância às experiências do passado, Aristóteles, por exemplo, não achava possível uma imitação da ação de um indivíduo simplesmente em vista da ocasião na qual se encontra.

A equiparação dedutiva da natureza humana feita por Aristóteles é a de que todos são políticos, ou seja, o convívio em sociedade é algo natural, inato ao homem. Em vista disto, a educação tem uma função formadora de hábitos e virtudes que acompanharão o indivíduo por toda a vida, assim como os vícios o acompanharão se não tiver uma boa educação. Por este prisma, esperasse que o indivíduo, cuja disposição é bem constituída, aja sempre em vista da virtude tornada hábito. A consequência da ação ainda está em segundo plano nesta perspectiva de valoração do agir, primeiro vem a virtude criada por disposição juntamente a sua expressão no desenrolar da ação. A ideia aristotélica de felicidade se pauta pela ação (energeia), essa significa "o exercício ativo das faculdades da alma humana em conformidade com a virtude, ou se houver diversas virtudes, em conformidade com a melhor e mais perfeita delas."(ARISTÓTELES, [19-], EN I 1098a1 15-19).

Maquiavel não é avesso ao trato das virtudes no processo de organização social e formação do cidadão, pelo contrário, ele argumenta que quanto mais a educação e a religião fortalece a busca das virtudes mais a república ganha. No entanto, como estamos a defender, o foco posto pelo Florentino está na consequência, no desenrolar das ações empreendidas no seio político da sociedade e da importância

CERQUEIRA, Marcone Costa. Todos os homens são maus, mas alguns são bons exemplos: considerações sobre a imitação no pensamento maquiaveliano. Griot : Revista de Filosofia, Amargosa - BA, v.18, n.2, p.14-33, 
destinada à imitação de tais ações. Ao aludir à educação dos antigos, Maquiavel está aludindo, principalmente, à educação dos romanos e sua efetividade no seio político. Haja vista sua demonstrada reflexão sobre a história romana e seus fundamentos, é fácil perceber os traços que estão a preencher a concepção da leitura maquiaveliana.

É necessário perceber que a sociedade romana estava muito bem referenciada em uma base estritamente cultural em relação à formação dos indivíduos, principalmente em seu início. "Numa primeira fase, a arcaica, de base rural, a educação assenta na tradição (mos maiorum), na reverência para com os mais velhos e para com os deuses (pietas), no valor do paradigma (histórias como as de Múcio Cévola, horácio Cocles e outras)". (PEREIRA, 2002, p. 196.) Esta construção perpassava as instituições romanas, desde a família até ao próprio senado. "A tradição constitucional (instituta, mos, consuetudo) tem sob a república um enorme espectro variado, indo das bases de leis não escritas - ius, mesmo que não scriptum até ao que se pode chamar mos, como as coisas se davam no tempo". (LINTOTT, 2009 , p. 04):

No mos maiorum estão contidas as principais expressões dos valores que constituíram a tradição romana em sua base mais primeva. A especificidade da formação da sociedade romana impingiu a necessidade de se estabelecer bases sólidas de valorização das relações entre os indivíduos. A falta de um referencial social comum na incipiente formação da cidade, pelo menos no que tange à arregimentação de indivíduos de diversas origens, levou à necessidade de construção de um referencial próprio.

Este processo representa o cerne de formação da sociedade romana e sua singularidade em relação às outras culturas que a influenciaram, mesmo diante de todos os aspectos de sincretismo que possam se apresentar. A educação do indivíduo dentro da sociedade romana é antes de mais nada a formação de um novo cidadão, os valores coletivos do grupo são transmitidos desde a relação parental da criança até a mais rígida formação militar dos jovens adultos. Assim nos informa Pereira (2002, p. $196-198)$ :

\footnotetext{
A partir dos sete anos, é o pai o educador. Um exemplo muito famoso é o de Catão-o-Antigo, que, segundo a biografia que dele fez Plutarco, não admitia que um escravo ralhasse ao filho ou lhe puxasse as orelhas, por ser lento a aprender... [...] A educação familiar termina, regra geral, aos dezasseis anos, com a tomada da toga viril. Segue-se um ano de aprendizado no fórum (tirocinium fori), com um amigo da família notável e idoso (no séc. I a.C., temos o conhecido exemplo de Cícero a escutar Quinto Múcio Cévola Áugure e Quinto Múcio Cévola Pontífice). Depois, o serviço militar, para o qual o jovem fora preparado pelos exercícios físicos, executados, não com uma finalidade agônica, como entre os Gregos, mas para alcançar maior destreza e força.
}

Certamente que se tem aqui um referencial comum entre muitas das civilizações antigas, o indivíduo é suprassumido pela coletividade, o sujeito é pertencente ao conjunto de sujeitos que formam sua comunidade. $O$ senso de pertença social do indivíduo é a base de sua adesão aos valores que lhe são transmitidos no transcurso de sua vida.

CERQUEIRA, Marcone Costa. Todos os homens são maus, mas alguns são bons exemplos: considerações sobre a imitação no pensamento maquiaveliano. Griot : Revista de Filosofia, Amargosa - BA, v.18, n.2, p.14-33, 
Este simples arranjo social, na maneira como se estabelece a relação dos indivíduos em seu processo de assimilação ao grupo, já é o suficiente para se embasar diversos valores nevrálgicos ao conjunto da tradição romana. Entre eles podemos elencar a Honor, a Dignitas, a Glória e a Gravitas, sendo todos valores presentes na tradição e intrinsecamente estipulados em vista da ação do indivíduo na vida política. Estes valores eram expressão da ênfase dada ao agir do indivíduo na vida política da sociedade, eram aquisições pessoais, ou seja, a liberdade e as leis são para todos, mas a Dignitas, a Honor, a Glória, são reconhecimentos conquistados pelo valor da ação individual. Tal valor é mensurado por seu significado em relação ao bem comum e defesa da pátria. Os exemplos dos homens que conquistavam tais distinções passavam à fazer parte do paradigma (exemplum). O que Maquiavel extraí desta tradição é o incentivo à imitação da ação, o exemplum, das ações vitais para manutenção do bem comum e da liberdade da república.

Para Maquiavel a imitação das ações valorosas em suas consequências para o bem da república, como já dissemos, não está presa à limitações do tempo, do lugar ou da cultura. Os fatores que permitem sua postulação: a equiparação dedutivauniversal da natureza humana, a atemporalidade das paixões e da ocasião, ainda estão presentes entre os modernos. No entanto, eles foram obliterados pela fraqueza impingida pela educação da religião cristã, ou pelo menos, na interpretação que se fez dela. O principal uso que o Florentino fará deste princípio está no âmbito da política, a imitação das ações contundentes será atrelada ao conhecimento do passado e à precaução contra o futuro, tendo como baliza o uso da virtù.

\section{O fator político}

O pensamento político maquiaveliano não deve ser cindido em dois, ou seja, não existe um Maquiavel republicano (Discorsi) e um principesco (De Principatibus), é preciso entender sua compreensão do caráter flexível e mutável das formas de governo e sua serventia para o influxo do corpo político no trânsito da história. "A preferência de Maquiavel pela constituição republicana se evidencia claramente nos Discursos. Seria de estranhar se assim não fosse". (HALE, 1963, p. 156). Porém, não dispomos de espaço para deslindar todos os meandros desta assertiva, no entanto, postulamos que o princípio da imitação é válido tanto dentro do processo republicano quanto no processo principesco. $\mathrm{O}$ que diferencia o uso da imitação neste dois processos é a característica das ocasiões e dos fins colimados para as ações empreendidas em vista do arranjo político. Para Maquiavel, apesar de sua aparente adesão a uma influência polibiana, as duas formas de governos majoritariamente vistas na história humana são repúblicas ou principados. Em suas palavras: "Todos os estados, todos os domínios que tiveram e têm império sobre os homens, são estados e são ou república ou principados". (MACHIAVELLI, 1954, P. I.)

Este movimento não representa um reducionismo teórico de Maquiavel sobre a teoria das alternâncias de governo, ao contrário, reflete sua tendência a extrair da história a maneira mais objetiva de estabelecer seus parâmetros. Neste processo ele acaba por depurar mais facilmente as ocasiões nas quais a destruição ou o florescimento do governo são mais exequíveis. A lógica da imitação segue também este cálculo, ou seja, quais ações em quais ocasiões de necessidade política podem ser

CERQUEIRA, Marcone Costa. Todos os homens são maus, mas alguns são bons exemplos: considerações sobre a imitação no pensamento maquiaveliano. Griot : Revista de Filosofia, Amargosa - BA, v.18, n.2, p.14-33, 
tomadas como referenciais. Sendo assim, a única diferenciação válida, no que tange o estudo da ideia de imitação, é entre as ações com vistas à se fundar, renovar ou manter a estabilidade do Estado, isso no caso dos indivíduos com cargos de liderança. No caso dos indivíduos comuns todas as ações devem seguir os exemplos que contribuem para o bem comum, tanto na república quanto no principado.

Está bem clara a posição de Maquiavel sobre a possibilidade de se tomar a imitação das ações do passado em sentido amplo, não apenas retórico ou aproximado, sua querela com os eruditos de sua época assenta-se exatamente nesta questão. Tomemos mais uma vez seu relato:

\begin{abstract}
No entanto, no ordenar as repúblicas, no manter os Estados, no governar os reinos, no ordenar a milícia e administrar a guerra, no julgar os súditos, no acrescer o império, não se encontra príncipe nem república que aos exemplos dos antigos recorra. [...] Donde nasce que vários que leem a história contentam-se em vislumbrar os vários acontecimentos passados, sem pensar, porém, de imitá-los, julgando a imitação não só difícil, mas impossível. Como se o Céu, o Sol, os elementos e os homens fossem diferentes em modo, ordem e poder, daqueles que eram antigamente. Querendo, portanto, tirar os homens deste erro, julguei necessário escrever sobre todos aqueles livros de Tito Lívio que não foram estragados pela malignidade do tempo... (MACHIAVELLI, 1954, D. I. Proemio.)
\end{abstract}

Tendo em mente os fatores atemporais que orbitam o núcleo da antropologia maquiaveliana, podemos sim asseverar que o florentino acredita que os indivíduos podem, e devem, valer-se dos exemplos dos antigos para lograrem êxito em suas próprias ações. Sucintamente, buscaremos delinear as diferenciações válidas para expor a aplicabilidade da ideia de imitação, começando pelo caso dos indivíduos comuns e passando depois para o caso dos indivíduos em posição de liderança e governo.

Ao escrever os Discorsi, Maquiavel toma como objetivo discorrer sobre três fatores importantes para a compreensão do sucesso de Roma, a saber: o que os romanos fizeram para organizar a república; o que fizeram para expandir seu império $^{6}$; os exemplos dos indivíduos comuns que se destacaram por suas ações ${ }^{7}$. Temos expresso aqui o espírito, verdadeiramente, republicano do secretário florentino, o fio condutor que perpassa todo os Discorsi é a temática da ação do povo romano enquanto conjunto. Mesmo no caso dos fundadores ou legisladores, a compreensão é a de que mesmo eles são parte do povo, ou seja, o indivíduo em tal condição é apenas um indivíduo em posição destacada. No que concerne aos umori a premissa também é válida, uma vez que na concepção maquiaveliana de sociedade o antagonismo entre eles é vital para a estabilidade política da república e sua liberdade.

Ao estabelecer uma retomada da ação política nos moldes que se tornaram característicos da tradição romana, Maquiavel está evocando, antes de mais nada, o lugar do político na antiguidade clássica, sua materialidade e efetividade. A despeito de toda a construção retórica e pitoresca que se fará da antiguidade nos textos

6 Ver D. II. Proemio.

7 Ver D. III, 1.

CERQUEIRA, Marcone Costa. Todos os homens são maus, mas alguns são bons exemplos: considerações sobre a imitação no pensamento maquiaveliano. Griot : Revista de Filosofia, Amargosa - BA, v.18, n.2, p.14-33, 
humanistas do Renascimento, o enfoque empregado pelo Florentino aludirá mais à perene construção das relações políticas empreendidas pela ação dos indivíduos do que a alegórica fruição dos ideais clássicos de erudição ou cultura. Sobre esta questão, vejamos a exímia observação de Gilbert (1996, p. 105):

\begin{abstract}
Ele cresceu, viveu e trabalhou em um mundo onde os problemas e as ideias políticas não podiam mais serem compreendidas a partir de um quadro intelectual tradicional. Suas capacidades criativas o conduziram a uma síntese nova. Mas, deve-se acrescentar, ele teve um impulso particular: a posição da qual ele considerava o mundo político era diferente daquelas de seus contemporâneos que escreveram sobre política. Ela não era nem aquela dos humanistas nem aquela dos aristocratas de Florença.
\end{abstract}

Metaforicamente pode-se dizer que Maquiavel está mais centrado na força do martelo que molda o granito social e menos na técnica desenvolvida pela mão do escultor que a esculpe. Por este prisma, a construção do político se dá no âmbito da alternância dos cenários sociais causada pelas consequências das ações empreendidas pelos indivíduos em vista do império da necessidade. As formas de governo, principalmente a república, se adequam a matéria social que resulta desta relação inelutável, o perpétuo movimento político impingido pelo agir dos indivíduos face a incontrolável mudança dos tempos. "O aspecto do pensamento político de Maquiavel em que sua dívida intelectual para com a tradição romana de civilis scientia é particularmente evidente é a sua teoria da República". (VIROLI, 2004, p. 05).

O motor da dinamicidade intrínseca a esta construção política é por conseguinte a valorização de cada ação, individual ou coletiva, que se realiza nos meandros constitutivos do tecido social. "Esta mudança na maneria de pensar sobre a relação entre ação e circunstâncias é, primeiro, articulada por Maquiavel concebendo a história em um efeito de ação livre". (VATTER, 2000, p. 07). A despeito daquilo que se tornou o foco da retomada humanista do ideal clássico, mais próximo da forma que do conteúdo, a preocupação de Maquiavel é antes com o conteúdo final do conjunto das ações dos sujeitos que constituem o político. Em vista disto, uma ação tem validade enquanto parâmetro de exemplo político quando é claramente expressa em suas consequências, a construção de exemplos erigidos apenas em intenções virtuosas, sem terem sido aprovadas pelo crivo da experiência, não se sustentam.

Estas ações empreendidas no cenário político, por indivíduos comuns, ressoam como exemplo e como lastros para o recurso das leis e dos costumes vitais à boa ordem social. Maquiavel dá um enorme peso ao reconhecimento social destas ações, tanto por parte dos indivíduos de boa índole quanto por parte dos celerados. $O$ que nos chama a atenção é exatamente a percepção, expressa por Maquiavel, de um compromisso coletivo dos indivíduos, ou melhor, de uma preocupação em reconhecer sua pertença ao corpo social ao ponto de envergonha-se por destoar das ações valorosas, como segue:

Nasce ainda este retorno das repúblicas em direção ao seu princípio a partir da simples virtude de um homem, sem depender de alguma lei que os estimule por alguma obrigação: não obstante, são de tais reputações e de tanto exemplo que os homens bons desejam imitá-lo, e os maus se

CERQUEIRA, Marcone Costa. Todos os homens são maus, mas alguns são bons exemplos: considerações sobre a imitação no pensamento maquiaveliano. Griot : Revista de Filosofia, Amargosa - BA, v.18, n.2, p.14-33, 
envergonham a ter uma vida contrária à deles. Aqueles que em Roma, particularmente, fizeram estes bons efeitos foram: Horácio Cocles, Scevola, Fabrício, os dois Décios, Rêgulo Atílio e alguns outros, os quais, com seus exemplos raros e virtuosos fizeram em Roma quase o mesmo efeito que fariam as leis e as instituições. (MACHIAVELLI, 1954, D. III, 1).

Esta influência dos bons exemplos precede um recurso mais incisivo, os castigos, para que a estabilidade e a ordem da república sejam mantidos. Neste sentido, a imitação dos bons exemplos, dentro do processo republicano, dá a argamassa que melhor sedimenta o corpo político. Como salientamos no segundo tópico, a educação dos romanos convergia para a valorização e o incentivo de tais ações que se demonstrassem incisivas e profícuas ao bem comum. A honra, a dignidade e a glória eram deferências concedidas política e socialmente aos indivíduos que se destacavam por estes meios extraordinários no convívio na república. "Assim considerada, a gloria é público reconhecimento das qualidades do cidadão. É a "fama por atos bons e grandes serviços para a res publica, que se comprovam pelo testemunho dos homens notáveis ou pelo da multidão" - definiu Cícero nas Filípicas I. 12.29”. (PEREIRA, 2002, p. 345).

Maquiavel resgata esta perspectiva da educação romana e de sua organização político-social, contrapondo-a à educação imposta pela religião moderna, ele faz o resgate da valorização da ação dos indivíduos no cenário político e o incetivo à sua imitação por parte daqueles que querem também serem reconhecidos. Esta busca de reconhecimento, ou glória, não é nociva, antes, é um dos fatores de incentivo à execução de ações que visem o bem da república, está acessível a todos os indivíduos. Ouçamos novamente o Florentino:

E de todas as três coisas que dão no princípio boa reputação a um indivíduo, nenhuma a dá maior que a terceira: porque a primeira, dos antepassados e dos pais, é falaciosa e não se sustém, em pouco tempo se consome, quando a virtù própria do indivíduo avaliado não o acompanha. A segunda, a de se fazer conhecido por suas companhias, é melhor que a primeira, mas é muito inferior que a terceira: porque não se funda em sinais que nasçam de ti, ficando sua reputação fundada sobre a opinião alheia, a qual é facilmente anulada. Mas a terceira, sendo iniciada e fundada sobre fatos e sobre sua própria ação, de ti dá no início tanta reputação que são necessárias várias obras contrárias àquelas para as anular. Devem, portanto, os homens que nascem em uma república trilharem este caminho e empenhando-se em alguma ação extraordinária começar à revelar-se. (MACHIAVELLI, 1954, D. III, 34).

Podemos intuir daí que, assim como Maquiavel postula que todos os homens são maus, acredita também que todos são capazes de ações valorosas no convívio político em prol do bem comum. Isso não que dizer que ele nivele todos os homens em um patamar, ao contrário, sua crença na capacidade extraordinária de indivíduos excepcionais é clara.

Pensemos então, a partir desta colocação, sobre a busca da glória e do reconhecimento por parte destes indivíduos excepcionais, os quais em geral se encontram em posições de liderança e governo. Como temos asseverado até aqui, Maquiavel não é um autor cindido em duas tradições, ou seja, não é um republicano

CERQUEIRA, Marcone Costa. Todos os homens são maus, mas alguns são bons exemplos: considerações sobre a imitação no pensamento maquiaveliano. Griot : Revista de Filosofia, Amargosa - BA, v.18, n.2, p.14-33, 
em tempo integral e um absolutista nas horas vagas. Sua crença na alternância das formas de governo de acordo com a alternância da matéria social e da necessidade impingida pelo tempo é inconteste. Como afirma o próprio Maquiavel:

\begin{abstract}
...nenhum Estado se pode ordenar que seja estável, se não é ou verdadeiro principado ou verdadeira república, porque todos os governos postos entre estes dois são defeituosos, a razão é claríssima: porque ao principado há um só caminho à sua estabilidade, a qual é descer em direção a república; e assim à república há somente um caminho para estabilizar-se, a qual é subir em direção a um principado. Os Estados do meio têm dois caminhos, podendo subir em direção ao principado ou descer em direção à república: de onde nasce sua instabilidade. (MACHIAVELLI, 1954, Discursus, § 11).
\end{abstract}

Variando entre república e principado o corpo político sempre carecerá da existência de bons exemplos que sirvam de parâmetros para a imitação. No entanto, os indivíduos que ocupam cargos de liderança, em vista das capacidades excepcionais que possuem, tem a dupla tarefa de: se pautarem pelas lições extraídas das ações dos grandes indivíduos do passado, avaliando tais lições em vista da ocasião e da alternância do tempo em que estão inseridos ${ }^{8}$; bem como serem eles mesmos exemplos dignos de imitação e incentivo ao cultivo de ações valorosas por parte dos indivíduos comuns ${ }^{9}$.

Nestes dois movimentos estão contidos algumas das ideias já trabalhadas até aqui, no primeiro caso, a imitação que o governante faz dos homens do passado deve ter como premissas de cálculo a ocasião, as paixões e a alternância dos tempos. Ou seja, a imitação das ações do passado levam em conta os fatores atemporais, a ocasião, nas quais geralmente as mesmas consequências são vistas; bem como as paixões que movem os homens. No entanto, o homem excepcional e de incomum Virtù, deverá saber adequar-se ao tempo no qual está inserido, sendo esta a principal marca de seu caráter extraordinário. Nas palavras do Florentino:

Tenho considerado muitas vezes como sendo a razão da má e da boa fortuna dos homens o modo como se adequam a seu tempo: porque se vê que os homens procedem em suas ações, alguns com ímpeto, alguns com respeito e com cautela. E porque, num e noutro destes modos se passam os termos convenientes, não se podendo observar o verdadeiro caminho, num e noutro se erra. Mas, o que vem a errar menos e a ter a Fortuna mais próspera, é aquele que adequa, como disse, os seus modos ao seu tempo, nunca procedendo segundo o força sua natureza. (MACHIAVELLI, 1954, D. III, 9).

Neste ponto temos uma interessante posição da teoria maquiaveliana, sua percepção de que tal cálculo, incluindo as lições dos indivíduos excelentes, mais o reconhecimento da ocasião e seus desdobramentos, mais a adequação de seu agir a seu tempo, é mais válido que uma virtude que se tenha tornado hábito no indivíduo, como queriam os gregos. Como explicitamos no segundo tópico, a educação dos gregos preconizava a formação de uma virtude que se instaurava no indivíduo como

8 Ver P. XIV.

9 Ver. P. XXI.

CERQUEIRA, Marcone Costa. Todos os homens são maus, mas alguns são bons exemplos: considerações sobre a imitação no pensamento maquiaveliano. Griot : Revista de Filosofia, Amargosa - BA, v.18, n.2, p.14-33, 
hábito e o guiava em todas as ocasiões. Essa era uma forma de controlar a natureza humana errática e propensa ao vícios, levando o indivíduo a um agir virtuoso. Ao que vemos, para Maquiavel, o indivíduo de Virtù, ao estabelecer seu cálculo de ação, vence a força errática de sua natureza ao avaliar todos as variáveis que influenciam seu agir. Nem virtude tornada disposição, nem natureza, o que guia o indivíduo excepcional é a avaliação das consequências de sua ação em vista do fim desejado. Por este prisma, pode-se entender a centralidade que Maquiavel dá a ideia de imitação e sua viabilidade enquanto premissa para o cálculo do governante.

No que concerne à segunda tarefa do indivíduo que se encontra em posição destacada de governo, seja uma república ou principado, é necessário apontar alguns aspectos centrais, e por isso mesmo, polêmicos. $O$ primeiro deles é o seu papel de exemplo a ser imitado pelos indivíduos comuns, como já ressaltamos, Maquiavel defende a tese de que o corpo político pode se regenerar ou se manter estável a partir da influência de um indivíduo que inspire os demais. Neste sentido, a imagem do príncipe carrega em si mesma um peso muito grande para a própria estabilidade e regeneração do Estado. Tendo em mente o fato de que Maquiavel defende a ideia de que uma república tornar-se estável, após corromper suas instituições, somente a partir da instauração de um principado, o exemplo do príncipe é preponderante para este movimento.

Seguindo esta linha, é plausível acreditar que a questão da aparência que o príncipe deve sustentar, tão discutida nos termos de um ardil de dissimulação e manutenção do poder, possa ter como principal função, na organização interna do corpo político, manter a inspiração dos indivíduos comuns a agirem para o bem comum e renovação do Estado ${ }^{10}$. Prova do contrário, ou seja, dos maus exemplos que causaram a degeneração da Itália, é indicada por Maquiavel por meio da denúncia dos líderes da Igreja, os mesmos que deveriam zelar pelos exemplos que inspirassem a ordem e a virtude ${ }^{11}$.

O segundo aspecto, dentro da segunda tarefa dos indivíduos que estão em posição de destaque, é a busca da glória. Como dissemos, a busca do reconhecimento, da glória e da honra são incentivadas por Maquiavel, bem como eram centrais na educação e organização da sociedade romana. Maquiavel se vale de uma argumentação retórica para defender a busca da glória, mesmo que individual, sempre em submissão ao bem comum. O Florentino faz uma espécie de gradação das ações que merecem mais glória e honra, sendo bem claro ao submeter as maiores glórias às ações que fundam e renovam uma república ou religião. É claro que tais glórias são de caráter muito restrito, no entanto, ao desenvolver a ideia da imitação Maquiavel instiga os indivíduos comuns a almejarem sua parcela de reconhecimento, por mais diversa que seja. Como segue:

Entre os homens louvados são os mais destacados aqueles que são postos como líderes e fundadores de religião. Logo depois aqueles que fundaram ou república ou reino. Depois destes são celebrados aqueles, à frente de

10 Certamente é uma postulação imbricada e suscetível de inúmeras detrações, no entanto, não poderemos, por limitação de espaço e objetivo, dirimir todas os pontos que a sustentam. Esperamos que dentro da coerência do restante do texto ela possa ser entendida como desdobramento da tese defendida.

11 Ver D. I, 12.

CERQUEIRA, Marcone Costa. Todos os homens são maus, mas alguns são bons exemplos: considerações sobre a imitação no pensamento maquiaveliano. Griot : Revista de Filosofia, Amargosa - BA, v.18, n.2, p.14-33, 
exércitos, tem ampliado seu reino ou aquele da pátria; estes se juntam os homens letrados. [...]. E qualquer outro homem, o número dos quais é infinito, se atribui uma parte de louvor, a qual lhe confere sua arte e ocupação. (MACHIAVELLI, 1954, D. I. 10).

Este movimento, a que definimos como retórico, faz coro à já explicitada tradição romana, na qual a glória e a honra não podiam ser conquistadas à não ser em vista das ações empreendidas em prol do bem comum e da liberdade. Este jogo retórico de atrelar à glória pessoal, paradoxalmente, a promoção da liberdade, da renovação e do bem comum da república faz complemento à assertiva maquiaveliana de que o indivíduo excepcional imita sempre as ações dos homens mais excelentes ${ }^{12}$. A exortação à busca da glória impulsiona o príncipe a desejar o governo de um Estado corrompido, podendo assim angariar para si uma das maiores glórias possíveis ao restabelecer a ordem e a liberdade de tal Estado ${ }^{13}$.

Em ambos os casos dos quais tratamos neste tópico, seja um indivíduo comum, seja um chefe de Estado ou príncipe, a ideia de imitação traça um elo entre a liberdade política da pátria e a busca de reconhecimento do indivíduo. É certo que para Maquiavel a república é a forma de governo mais duradoura, sendo também a que apresenta maior ocorrência de indivíduos que através das consequências de suas ações contundentes, e da capacidade de se adequarem às necessidades impostas pelos tempos, garantem a liberdade e o viço do corpo político ${ }^{14}$. Não obstante, a equiparação dedutivo-instrumental de que todos os homens são maus, não anula a possibilidade da existência de uma virtude cívica, pautada nos exemplos das ações contundentes que se traduzem em liberdade na república. Uma sociedade que leve os indivíduos à serem mais amantes da liberdade e a estimarem a glória mundana.

\section{Conclusão}

É inegável o tom pessimista e até uma tanto catastrófico da afirmação do Florentino de que todos os homens são maus, parece carregada de desilusão em relação ao convívio político. Porém, como buscamos demonstrar ao longo desta argumentação, tal perspectiva não se coaduna à real disposição do autor dos Discorsi, nem justifica difamar a mente que deu vida ao De Principatibus. Maquiavel demonstra uma cara admiração pelos grandes exemplos dos excelentes homens que ele pode conhecer através dos relatos históricos e de suas viagens pelas diversas cortes europeias.

A construção de uma república ou um principado, está ancorada na existência de indivíduos que possam servir de exemplo de compromisso e devoção aos princípios fundantes de tal governo. Para Maquiavel este processo dever ser garantido, ampliado e renovado pela via da educação, pela valorização política dos indivíduos e pela distinção social daqueles que demonstram os valores necessários para a manutenção e crescimento da pátria. A questão da maldade nos indivíduos se assenta

12 Ver P. VI.

13 Ver D. I, 10.

14 Ver D. III, 9.

CERQUEIRA, Marcone Costa. Todos os homens são maus, mas alguns são bons exemplos: considerações sobre a imitação no pensamento maquiaveliano. Griot : Revista de Filosofia, Amargosa - BA, v.18, n.2, p.14-33, 
exatamente na ausência de tais valores e na negligência dos princípios políticos e sociais que garantem o bem-estar do corpo político, seja república ou principado.

Em vista disto, Maquiavel não é um moralista que prega a total ruína da natureza humana e a inescapável necessidade de constrição arrependida de todos os erros morais. Antes, ele é um pensador político que percebe nas relações sociais um realismo capaz de mudar a disposição dos indivíduos, tendo a imitação um papel crucial neste processo. Desta forma, acreditamos ter demonstrado, mesmo que sucintamente, a viabilidade de se pensar a construção de um governo estável, lastreado por instituições justas, dentro do escopo maquiaveliano. A aparente negatividade de sua concepção antropológica não impossibilita este processo, sendo na verdade uma maneira de regulá-lo e direcioná-lo para uma construção coletiva dos indivíduos sociais.

CERQUEIRA, Marcone Costa. Todos os homens são maus, mas alguns são bons exemplos: considerações sobre a imitação no pensamento maquiaveliano. Griot : Revista de Filosofia, Amargosa - BA, v.18, n.2, p.14-33, 


\section{Referências}

AMES, José Luiz. Maquiavel: a lógica da ação política. Cascavel: Edunioeste, 2002. ARISTÓTELES. Éthique de Nicomaque. Texte, traduction, préface et notes par Jean Voilquin. Paris: Garnier Fréres, [19-]

GILBERT, Felix. Machiavel et Guichardin: Politique et histoire à Florence au XVI ${ }^{\mathrm{a}}$ siècle. Traduit par Jean Viviès et Perle Abbrugiati. Paris: Éditions Du Seuil, 1996.

GILSON, Étienne. Introdução ao estudo de santo Agostinho. Tradução de Cristiane Negreiros Abbud Ayoub. São Paulo: Discurso Editorial; Paulus. 2006.

GRAMSCI, Antonio. Maquiavel, a política e o Estado Moderno. Tradução de Luiz Mário Gazzaneo. 7 ed. Rio de Janeiro: Civilização Brasileira, 1989.

HALE, J. R. Maquiavel e a Itália da Renascença. Tradução de Waltensir Dutra. Rio de Janeiro: Zahar, 1963.

HASLAM, Jonathan. A necessidade é a maior virtude: o pensamento realista nas relações internacionais desde Maquiavel. Tradução de Waldéa Barcellos. São Paulo: Martins Fontes, 2006.

LEFORT, Claude. Les formes de l'histoire: essais d'anthropologie politique. [S.l.]: Gallimard, 1978.

LINTOTT, Andrew. The constitution of the Roman Republic. 2 ed. New York: Oxford University Press, 2009.

MACHIAVELLI, Opere. A cura di Mario Bonfantini. Milano/Napoli: Riccardo Ricciardi Editore, 1954.

NAMER, Emile. Machiavel. Paris: Press Universitaires de France, 1961.

NATALI, Carlo. L'action efficace: études sur la philosophie de l'action d'aristote. Paris: Éditions Peeters, 2004.

PEREIRA, Maria Helena da Rocha. Estudos de história da cultura clássica: cultura romana. 3 ed. Lisboa: Fundação Calouste Gulbenkian, 2002.

PINZANI, Alessandro. Ghirlande di fiori e catene di ferro: istituzioni e virtù politiche in Machiavelli, Hobbes, Rousseau e Kant. Firenze: Le Lettere, 2006.

Maquiavel \& O Príncipe. Rio de Janeiro: Jorge Zahar Editor, 2004.

RORTY, Richard. A filosofia e o espelho da natureza. Lisboa: Dom Quixote, 1988.

SARANYANA, Josep-Ignasi. A filosofia medieval: das origens patrísticas à escolástica barroca. Tradução de Fernando Salles. São Paulo: Instituto Brasileiro de Filosofia e Ciência "Raimundo Lúlio", 2006.

SKINNER, Quentin. Maquiavel. Tradução de Denise Bottmann. Porto Alegre: L\&PM, 2012.

VATTER, Miguel E. Between form and event: Machiavelli's theory of political freedom. Dordrecht. Boston : Kluwer Academic Publishers, 2000.

VETÖ, Miklos. O nascimento da vontade. Tradução de Álvaro Lorencini. São Leopoldo: Unisinos, 2005.

VIROLI, Maurizio. Machiavelli. New York: Oxford University Press, 2004.

Autor(a) para correspondência: Marcone Costa Cerqueira, Universidade Federal de Santa Catarina, Centro de Filosofia e Ciências Humana, Trindade, CEP 88040-970, Florianópolis - SC, Brasil. markantfilos@yahoo.com.br

CERQUEIRA, Marcone Costa. Todos os homens são maus, mas alguns são bons exemplos: considerações sobre a imitação no pensamento maquiaveliano. Griot : Revista de Filosofia, Amargosa - BA, v.18, n.2, p.14-33, 